\title{
Exploring Cell Turnover and Metabolism in Health and Disease with NanoSIMS
}

\section{Matthew Steinhauser}

\author{
University of Pittsburgh School of Medicine, Aging Institute, Pittsburgh, Pennsylvania, United States
}

Measurement of biological processes at the single cell or subcellular level is critical in order to better understand the heterogeneity of cell populations, particularly within the complex microenvironments of biological tissues. Nanoscale secondary ion mass spectrometry (NanoSIMS) enables multiplexed, quantitative imaging of the elemental composition of a sample surface at high resolution $(<50 \mathrm{~nm})$. Tuning a NanoSIMS instrument to capture two different isotopic variants of a given element provides nanoscale isotope ratio measurements. When coupled with stable isotope tracer methods, such isotope ratio measurements provide a quantitative window into biochemical pathways of relevance to tissue homeostasis and disease. This methodology has been applied to study fundamental metabolic processes, including glucose, amino acid, lipid, and nucleic acid metabolism and cell turnover. This presentation will demonstrate our recent published and unpublished experience applying these approaches to reveal new biological insights. Using administration of stable isotope tracers for DNA synthesis and de novo lipogenesis in mice and humans, we identified an age dependent decline in two aspects of adipose tissue plasticity, the birth of new adipocytes and adipocyte lipid turnover. Using a new method to track genetic labels intracellularly together with protein synthesis and turnover, we discovered unexpected heterogeneity of lysosomal protein age within individual cells. Finally, through administration of glucose and glutamine tracers to tumor bearing mice, we discovered that it was not just the degree of substrate utilization but metabolic heterogeneity that predicted a key metric of tumor growth. Key points of emphasis will include: (1) application- and experiment-specific tradeoffs between measurement accuracy and analytical throughput, (2) unexpected findings that emerge from performing quantitative measurements of individual cells in heterogeneous populations, and (3) the potential window into human biology with translational studies.

\section{References}

○ Steinhauser ML, Bailey AP, Senyo SE, Guillermier C, Perlstein TS, Gould AP, Lee RT, Lechene CP. Multi-isotope imaging mass spectrometry quantifies stem cell division and metabolism. Nature. 2012; 481(7382):516-9. PMCID: PMC3267887.

○ Kim SM, Lun M, Wang M, Senyo S, Guillermier C, Patwari P, Steinhauser ML. Loss of white adipose hyperplastic potential is associated with enhanced susceptibility to insulin resistance. Cell Metabolism. 2014. 20: 1049-58. PMCID: PMC4715375

○ Guillermier C, Fazeli PK, Kim S, Lun M, Zuflacht JP, Milian J, Lee H, Francois-Saint-Cyr H, Horreard F, Larson D, Rosen ED, Lee RT, Lechene CP, Steinhauser ML. Imaging mass spectrometry demonstrates age-related decline in human adipose plasticity. JCI Insight. 2017. 2(5):e90349. PMCID: PMC5333969

○ Guillermier C, Doherty SP, Whitney AG, Babaev VR, Linton MF, Steinhauser ML, Brown JD. Imaging mass spectrometry reveals heterogeneity of proliferation and metabolism in atherosclerosis. JCI Insight. 2019. 4(11): e128528. PMID: 31167964

○ Narendra DP, Guillermier C, Gyngard F, Huang X, Ward ME, Steinhauser ML. Coupling APEX labeling to imaging mass spectrometry of single organelles reveals heterogeneity in lysosomal protein turnover. J Cell Biol. 2019. PMID: 31719144 